\title{
Vibrio metschnikovii
}

National Cancer Institute

\section{Source}

National Cancer Institute. Vibrio metschnikovii. NCI Thesaurus. Code C86844.

A species of facultatively anaerobic, Gram negative, curved rod shaped bacteria assigned to the phylum Proteobacteria. This species is motile, oxidase negative, halophilic, hemolytic, cannot convert nitrate to nitrite and can use a wide variety of sugars as carbon sources. V. metschnikovii is a marine organism and can cause gastroenteritis. 